\title{
A FRASEOLOXÍA COMO FONTE LEXICOGRÁFICA
}

\author{
Xesús Ferro Ruibal \\ Centro Ramón Piñeiro para a Investigación en Humanidades
}

Dende os inicios da lexicografía xa houbo repertorios fraseolóxicos autónomos. Aínda así, os dicionarios comúns sempre incluíron cantidades variables de fraseoloxismos que exemplificaban valores semánticos das palabras que definían. E, para moitos usuarios, os fraseoloxismos que adornaban os dicionarios foron a primeira experiencia de fraseoloxía definida. Ora ben, se entendémo-la lexicografía como repertorio de voces e dos valores semánticos desas voces, o acomodo nela dos fraseoloxismos presenta algúns problemas de lindeiros.

Non representan problema ningún para un lexicógrafo as palabras únicas que só aparecen en combinación fraseolóxica (jVaites, vaites!) ou en contextos pluriverbais (tralalalá en cantigas coma Teu pai non-o ten, / túa nai non cho dá; /¿de donde che vén? /-Do tralalalá). Pero xa teñen a súa dificultade aquelas palabras comúns que na combinación fraseolóxica collen un valor semántico específico desa combinación. Un caso moi simple é o da palabra beira. Defínese normalmente como "s.f. Orilla" (Rodríguez 1863) e dese substantivo nacen as locucións aa veira "junto ó pegado", andúvolle aas veiras "le anduvo al rededor ó cerca, etc." (Cuveiro 1876). Pero noutras locucións xa aparece unha metáfora: facer as beiras "rondar, dar vueltas al rededor de alguno o siguiéndole continuamente para conseguir de él alguna cosa: hacer el oso, hacer la rosca del gallo" (DRAG 1913-1928), facerlle as beiras a unha cousa "desearla con ansia y hacer indirectamente los medios para conseguirla" ou facerlle as beiras a unha rapaza "rondarla, cortejarla, galantearla, hacerle el amor" (Eladio Rodríguez 1958-1961). Como se ve, este novo valor non é valor da palabra senón do conxunto fraseolóxico. E nos fraseoloxismos idiomáticos o significado global xa non resulta da suma dos significados dos seus compoñentes senón que é un valor novo que unicamente se activa no uso conxunto e fraseolóxico das palabras que o forman. Isto impide establecer cal das palabras é a por- 
tadora da nova carga semántica, a cal dos elementos do conxunto se lle debe asigna-lo núcleo semántico do fraseoloxismo.

En consecuencia, o fraseoloxismo non vale sempre para exemplifica-los usos que o dicionario recolle para esa voz, porque non sempre é doado. E, aínda que os lexicógrafos utilizan certas convencións razoables para alfabetizaren esas unidades, o acomodo da fraseoloxía nun dicionario convencional non sempre é satisfactorio. Así que, pouco e pouco, a fraseografía vaise independizando da lexicografía e multiplícanse nas librerías os dicionarios fraseolóxicos, exclusivamente fraseolóxicos, que responden a un corpus diferente e tamén a pautas de dicionarización específicas.

Pero neste traballo eu non vou tratar de fraseografía nin de idiomaticidade. Vou facer algo moi simple que saben tódolos lexicógrafos: só vou lembrar algúns refráns que poñen á mostra valores semánticos, variantes ou mesmo palabras que non aparecen nos dicionarios; ou que manteñen vivas palabras enxebres que o contacto de linguas vai substituíndo polas simétricas coas de linguas poderosas. Isto é o que quero comentar: que a fraseoloxía, entendida en sentido amplo, aínda é unha despensa léxica; e que algúns paremiólogos fixeron tamén de lexicógrafos. Como ven, todo é cousa sabida.

Cando falo de dicionarios (galegos), limitareime ós dicionarios incluídos no Diccionario de diccionarios de Antón Santamarina (2003b), esa marabillosa ferramenta, insuficientemente loada pero masivamente usada, que nos permite consultar vinteseis obras lexicográficas de maneira instantánea, cómoda e comparativa. E cando falo de refraneiros, refírome a dous refraneiros de mediados do século XX, un felizmente xa público (Francisco Vázquez Saco 1962) e outro aínda inédito (Vicente Llópiz 1954a e 1954b), de dous homes que adoitaban preguntarlles ós seus informantes o significado daquelas palabras que a eles lles resultaban pouco transparentes. As definicións deles reprodúzoas entre comiñas e na maior parte dos casos anotarei a localización tal e como eles a anotan.

O material non é escaso e voume limitar nesta ocasión ás palabras que empezan polas letras comprendidas entre o A e o L.

\section{ALGÚNS VALORES SEMÁNTICOS OQUE NON VEXO NO DICIONARIO DE DICIONARIOS OU QUE SON MOI INFRECUENTES}

Raro é o cazador de fraseoloxismos que non se sorprende cunha palabra ou coa acepción dunha palabra que non lle é transparente. Raro 
é o que, nesa situación, non pregunta ó seu informante e non anota a información que dá transparencia ó refrán ou á locución e que converte ese fraseoloxismo en ocasión dunha nota lexicográfica. Un home así era o comandante Vicente Llópiz Méndez, que encheu o seu refraneiro de notas lexicográficas, máis ou menos canónicas, pero abundantísimas. Poñamos un caso: ó refrán Ben coñez Cristo as pousas dos seus amigos, engádelle o comentario: "Pousas': moradas, aposentos”, definición que non é exactamente a mesma que ofrecen Pintos (1865) (“Quinta, granja, lugar; pr. la casa murada") ou Valladares (1884) ("Quinta, ó casa de campo y recreo. Guimarans è linda pousa; / mais Jimonde, sin disputa, / e mais qu'entrambas ainda / Santa Crus de Ribadulla) ou Leiras (ca. 1906) ("descanso"), conceptos que repiten dun xeito ou doutro os posteriores. Para Llópiz é simplemente "casa", maiormente se o equivalente latino que ofrece é tecta (Iesus Christus amicorum co[g]nosci[t] tecta suorum). Isto quere dicir que moitas coleccións fraseolóxicas atesouran nas notas ós refráns ou locucións un certo caudal lexicográfico que ofrece acepcións pouco coñecidas de certas palabras, converténdose en cita valiosa para documentar un determinado valor semántico minoritario. Vexamos algúns exemplos.

abafado. Mal abafado "mal de origen venéreo e inconfesable". Non [b]ai mal abafado que por muller non veña (Llópiz 1954a: 535,439). Ata o DRAG (1913-1928) non aparece o valor de "El que tiene mal color, inficionado, emponzoñado. Se dice que una mano, un pié, ú otra parte del cuerpo esta abafada, cuando se halla inflamada por haber tocado en algún reptil ó insecto venenoso". Eladio Rodríguez (1958-1961) é o que matiza "Corrido, avergonzado, insultado", pero o significado de "venéreo" non o menciona ninguén.

abeirarse. Refregarse [unha vaca] coas outras cando está en celo e mesmo montar nelas. Cando a vaca anda maronda, toda se abeira coas outras (Llópiz 1954a: 1,137). Nos dicionarios aparece esta palabra como 1. "Guarecerse; resguardarse de la lluvia o nieve (Acevedo 1932); 2. "v. r. Acercarse, aproximarse, irse hacia la orilla” (Eladio Rodríguez 1958-1961), pero non co significado que ten no refrán.

adoar. "Pasar la palma de la mano suavemente". Ao que dá esmola Dios ca man o adoa (Llópiz 1954a: Dios, 674,15). Adoar aparece en numerosos dicionarios como 1. "Afilar instrumentos cortantes" (Sobreira), 2. "Llevar la piel la navaja, cortar bien" (Pintos 1865), 3. "Perfecionar, alisar, pulir, redondear los cortes toscamente hechos en la madera" (Valladares 1884), formas que repiten os posteriores. Pero o significado que parece ter nese refrán non figura nos dicionarios.

argabazo. Bólas de bosta pegadas ó pelo das coxas das vacas e das ovellas. A máis boa meleciña para tira-lo argabazo, auga, freganzo e xabón por enriba e por embaixo (Llópiz 1954a: 2,450). Para esta palabra os dicionarios só repiten unha vaga definición de Sobreira: "Cada uno de los fragmentos que hacen la suciedad algo gruesa”, pero o significado que ten no refrán é máis específico.

arolar. Xaxuar. Cando o médico arola, o crego chora. Llópiz comenta: "No desayuna el médico, cuando por gran sanidad en su distrito, gana poco. Y habiendo mucha salud, tampoco hay muchos entierros, rogativas y votos por las dolencias". T. Saavedra, Paradela de Abeleda, Porquera, ref. 1210 (Llópiz 1954a: 508,230). 
arolas. Xaxún. Pan en arolas con romeu en frol, volverante a cara a boa color. Llópiz explica que pan en arolas é "pan en ayunas" e localízao en Muras de Eume (Llópiz 1954a: 515,300). Nos dicionarios arola é cuncha de marisco e mesmo existe a fórmula ;Vaite á arola!, que "equivale a vete a paseo, déjame en paz, no me molestes" (Eladio Rodríguez 1958-1961) e que, como moito, pódenos lembra-la época na que estar mantido a ostras era "ter cara de fame".

arrazada. [Vaca] recastada de vaca do país cun boi de raza selecta. Vaquiña arrazada, filla de casa pra gasallala (Llópiz 1954a: 1,155). Nos dicionarios aparece arraz̧ar só co valor de "escampar, parar de chover".

asesego. Pausadamente, sosegadamente. Asesego gánase o ceo (var. Con paciencia gánase o ceo) (Llópiz 1954a: Culto religioso, 577,55). Este uso como adverbio non o recolle dicionario ningún.

axe. Ocasión propicia, para mercar ou vender, na feira do gando. O que deixa pasa-lo axe, non se teña por bo feirante (Llópiz 1954a: 2,15). Os dicionarios dan estes valores: 1. "Eixo" (Porto 1900-1908); 2. "Insulto, desprecio, bochorno, desaire, injuria" (Filgueira et al. 1926); 3. "interj. (Gro.) voz que se emplea para meter a las gallinas en el gallinero y al cerdo en la cuadra” (García González 1985).

baceira. Bazo. Cando ó corpo lle engorda a baceira, cousa boa non lle espera (Llópiz 1954a: 2,453). A definición que dan os dicionarios é a da enfermidade do bazo.

bórea. "Pláceme, felicitación". Parto suado, agarda as bóreas. Dr. A. Vila (Llópiz 1954a: 517,308). O DRAG (1913-1928) define bórea como "Vocablo que a continuación de la frase vaite â, significa: vete a paseo, vete al diablo, vete enhoramala. El vaite â bórea, úsase mucho en Santiago y su comarca. Var: BÓRIA en su tercera acep.", e boria como 1 "s. f. Holgorio, algazara, diversión". 2. "s. f. Bolsa en la que los cerrajeros llevan sus herramientas". Borear é aínda hoxe palabra moi viva en Ferrol co significado de "armar barullo". Non me parece posible que Llópiz, que viviu a adolescencia en Ferrol, fose marrar nesta definición.

bragada. Parte baixa do ventre, entre as pernas e a cara interna destas. A vaca farta, do seu rabo fai bragada (Llópiz 1954a: 1,132).

brexeiro. Crego canaveiro teno por brexeiro. Llópiz define canaveiro como "escuálido, magro" e brexeiro como “tunante” (Llópiz 1954a: Frailes, curas, 97). Brexeiro só aparece en Carré (1928-1931) como “adj. Lugar bajo, pantanoso y lleno de zarzas y matorral”.

cachapa. Recipiente metálico. Mais tolino que unha cachapa de grilos. Llópiz (1954b: 10668) defíneo aquí como "bote de hojalata con agujeros". Aparella-la cachapa antes de merca-la vaca "facer preparativos para algo que aínda non é seguro que vaia suceder". Cachapa parece ter aquí o significado de "caldeiro de muxir", aínda que non se podería excluí-la acepción que dan maioritariamente os dicionarios: "s. f. Vaso aplanado de madera que llevan los segadores a la cintura, y que contiene agua y una piedra para afilar la hoz. En algunas comarcas se utiliza un cuerno de buey o vaca para el mismo objeto". Só Elixio Rivas (1978) recolle outro valor: “caxato".

cachazo. Pescozo da vaca. Aplícase tamén, en sentido vulgar e burlesco, á xente cando o ten groso de máis. Carne de vaca vella, bon cachazo saca (Llópiz 1954a). Este valor aparece tamén na Mezquita e en Ponteareas.

cacholudo. [Boi] de cornos grandes. O boi, cacholudo; e o faco, cascudo (Llópiz 1954a: 1,146).

cagalleira. Diarrea contumaz. Courizas e cagalleiras acaban cas vellas. Couriza sería a defluxión nasal (Llópiz 1954a: Medicina, 55. Dr. Llopiz Ferrer, Repertorio médico). O que din os dicionarios resúmese na proposta de Eladio Rodríguez (1958-1961): "s. f. Sitio en donde hay muchas cagallas de ganado lanar y cabrío; CAGALLADA. / Conjunto de cagajones que una caballería suelta en cada vez".

camarzo. "Achaque de jaqueca". Cabeza de home sano pouco sabe de camarzo (Llópiz 1954a. S. Vicente de Lobeira). A palabra figura nos dicionarios pero non co significado que lle dá Llópiz senón 
co de "Chasco, burla o engaño. Suceso contrario a lo que se esperaba" (Valladares 1896). "Levar camarzo, agotarse la cosecha, llevar una buena baja. Dícese también de una persona. Dar un bon camarzo a unba leira, cavando o sachándola casi toda. Levóu un bon camarzo o fruto de unha leira, estrago a causa del tiempo o del ganado, en Pena de Cabras. Logo lle das bon camarzo, a una cosa, a golpes, en Mestre" (Aníbal Otero 1977).

canivés. [Bovino] acanaveirado, fraco coma unha cana. Ó boi canivés a corna lle creq (Llópiz 1954a: 1,128). Nos dicionarios aparece como "s. m. Cerdo desmedrado que no crece ni engorda por mucho que coma" pero nunca se refire a un bovino.

carouquexa. "Especie de aftas o granulaciones en el paladar o lengua de los niños". Carouquexas dos nenos, cúranse ao solpór co biquiño no fontenlo. V. Risco. Notas para un refranero (Ourense, 1953) (Llópiz 1954a: Medicina, 53). Só en Eladio Rodríguez (1958-1961), Franco Grande (1968), Carré (1928-1931): “s. f. Especie de afta o llaguita blanca que se presenta en la mucosa bucal, y especialmente en la lengua de los niños" (Eladio Rodríguez 1958-1961).

carracho. [Boi] ruín, fraco, suxo. Ó boi carracho non lle falta argabazo. Os dicionarios só se refiren ó insecto que vive maiormente nos bovinos e nos cans e, figuradamente, á persoa "pequeña, molesta, importuna; miserable etc". Pero que un boi sexa carracho non o di máis ca este refrán.

carrán. Llópiz dá boi carrán como sinónimo de boi carracho do refrán anterior (Llópiz 1954a).

chisgar. Enfraquecer por esgotamento. Cada día tres ou catro, chisgan ó almallo (Llópiz 1954a: 1,137). Llópiz explica que o refrán alude ó exceso de cubricións a que se obriga a un boi do posto; que tamén se aplica figuradamente ó home mullereiro e acabado por este exceso. Recólleo de E. Borrás no Seixo, onda Ferrol. O verbo chisgar só aparece nos dicionarios co valor de "beber viño" ou "pechar un ollo" (e mesmo "quedar torto"). Pero dalgún xeito no ms. de Rodríguez (1855) xa se ve implícito ese valor no part. chisgado que ten o valor de "flaco, consumido, enjuto, seco, etc." que despois repiten case todos.

choca. Bóla de bosta pegada ó pelo da vaca. Á vaca fraca non lle faltan chocas e raña (Llópiz 1954a: 1,132).

chorar. Florear. Liño chorado, medio medrado. En S. Simón de la Cuesta, chorimas = flores y chorado $=$ floreado. Vázquez Saco di que a palabra chorado, en este sentido, "está ausente de muchos diccionarios" (Vázquez Saco 1962: 1599). Parece intuílo Carré (1928-1931) ("Plantear. Trazar o esbozar en líneas generales un asunto"), pero o valor de "echar flor el lino" non aparece ata Rivas (1978): "Florecer, echar la flor (Fondo de Vila): Xa chora o liño, ya empieza a echar la flor el lino. Este verbo, que sólo se usaba ya en relación con el lino, ha dejado de oírse desde que dejó de sembrarse el lino por el año 1965. En la Edad Media: chor, flor"). Tamén o recolle o Glosario de Constantino García González (1985) en Novefontes (“echar flor el lino”).

cibeira. Presebe. Por santa Cecilia, o boi á cibeira (Llópiz 1954a: 1,151). Santa Icía é o 22 de novembro e nese tempo xa van feitos os traballos agrícolas que precisan bois e estes xa levan un tempo descansando por gándaras e montes; os fríos sucesivos poden facerlle mal ó gando e por iso se aconsella recollelo na corte, onda o presebe (cibeira). Este valor de lugar onde se ceba o animal só parece coñecelo Carré (1928-1931). Nótese que cibo e ciballo son nomes da comida do gando.

cobro. Llópiz define o cobro como "simple hematoma o una tumidez maligna con obstrucción de los vasos sanguineos. Puede ser 'branca' o herpes, 'rubia' escarlatina, 'rosa' erisipela, y 'negra' pústula maligna”. O cobro, con que o matarás? Con unto sin sal e cinza do lar. / var. lixo do lar en vez de cinza y en este caso se refiere a las barreduras del fogón”) (Llópiz 1954a: Medicina, 58. El Brujo de Sedes). Só recolle esta acepción como segunda Carré (1972) “s. m. Cobro, cobranza. / Enfermedad, afección de la piel”. Con todo, Llópiz no comentario posterior a un ensalmo terapéutico (59) di que “también se le llama 'cobro' o ‘cobrón' en algunos lugares (Forcarey, Moaña, etc.) a las inflamaciones producidas por la picadura de bichos venenosos". 
coita. "Coitas e rábeas, manchas que salen en la piel a causa de disgustos recibidos". Coitas e rábeas, sal na auga, n'unha cunquiña de bidueiro e limparás o pelexo. El Brujo de Sedes Abon. por M. Abizanda y San Martín, ref. 6 (Llópiz 1954a: 463,63). Hai unha patoloxía non identificada que consiste nun "tumor do gando vacún que se forma no peito" que primeiro anotou Filgueira (1926) e que algúns identifican con carbuncho; pero o refrán fala claramente dunha erupción cutánea.

confiscante. Que acaba con todo o patrimonio. Fillo de comerciante, paseante; e do paseante, confiscante (Vázquez Saco 1962: 16744). A palabra non aparece en ningún dicionario pero pode deducirse sen problemas do valor de confiscar que recollen Eladio Rodríguez (1958-1961) (“v. a. Confiscar, privar, despojar de sus bienes al reo y aplicarlos al fisco o venderlos judicialmente") e García González (1985) (“v. (Cod.) sacarle los bienes a uno por no pagar los impuestos”), porque ó final o fisco intervén cando a segunda xeración xa non ten con qué pagar.

cóxegas. "Calambres, también llamados brecas, cuando son muy agudos; rodela, rótula de la rodilla (xollo, sollo, xoela o xionllo)". "Cóxegas collo nesta rodela deste meu xollo. Brecas traio, deixo brecas, diste men cóbado, diste men xollo. Retahila de los compostores algebristas para curar los calambres agudos, Moraña, Pontevedra" (Llópiz 1954a. Dr. Castro Meizoso: Algunas denominaciones). A breca aparece como "calambre" por primeira vez no DRAG (1913-1928).

culabrela. Certa ave de rapina que se mantén de réptiles. Culabrela, culabrela, pon o ollo na portela; pastorciños gardai ben que abi ven o come res, que nos come a todos tres. ¿Que ave é? Só Franco Grande (1968) e o Carré inédito din que culabrela é o nome da aguia nalgunhas comarcas. Lembremos, en cambio, o refrán que Vázquez Saco recolle na Gudiña (Se o corvo corvexa, o lobo rastrexa; corvo calado, lobo de lado) e que nos fai pensar noutra ave, o corvo, de quen di que acompaña o lobo nas súas correrías para aproveitarse das reses que este mata; de aí que a presenza do corvo avise os pastores da proximidade do lobo ou come res (Vázquez Saco 1962: 977).

dapexado. Pexado, animal trabado coa pexa ou acabramo que non lle deixa facer movementos rápidos nin continuados. Boi dapexado, non se sal do prado (Llópiz 1954a: 1,133). Curiosamente algúns dicionarios inclúen esta palabra pero co significado contrario de "libre, expedito".

debullar. Remoer, segundo Llópiz, en terras de Bande e Lobeira. Non lle tápe-la boca ó boi que debulla (Llópiz 1954a: 1,145). O que máis se achega é unha das acepcións de Eladio Rodríguez (19581961): "Consumir ávidamente los manjares de una comida".

escornada. Cornada. Ó boi escorneador nunca lle faltou a súa escornada (Llópiz 1954a). Só García González (1985) trae esta voz pero co significado de "adj. (Caa. Cab. Val. Ped.) dícese de la vaca a la que le falta un cuerno" (VGR, Llópiz 1954a).

esgorriar. Turrar, cornear. jMalas vacas te esgorrien! é antiga expresión de desagrado en Betanzos segundo Llópiz (1,505). O can ladra e o gato rabuña, a vaca esgorría e o furaño fura (Llópiz 1954a).

fuciñeira. Vetillo. Ó boi que macha/ malla non lle poñas fuciñeira (Llópiz 1954a).

gaita. Lavativa. Convencionalismos de ant. menciñeiros. Cinco gaitas valen o que unha purga Camilo Carbelle, Colec. de ref. ant. - Remoiño, Valle de Arnoya (Llópiz 1954a: 520,335). Este valor non aparece en ningún dicionario. Algunhas veces teño pensado que a este significado negativo, e non ó instrumento musical, poden estar aludindo os usos negativos da palabra gaita coma os que recolle Eladio Rodríguez (1958-1961): estar de mala gaita ("estar de mal talante"); é unba gaita ("dícese de lo que constituye un inconveniente o una dificultad”); iQué gaita me tras! (“'icon qué encomienda me vienes!").

gatuñeira. O boi vello a gatuñeira tira dos regos (Llópiz 1954a: 1,147). Só Rivas (1988) recolle esta palabra como "s. f. Sitio de gatuñas ou uñagatos (Fondo de Vila)". É a Ononis spinosa, tamén chamada detén-bois que corresponde ó castelán detiene buey, quiebraarados; portugués resta-boi; catalán afrontacavadors, que algúns científicos denominaron remora aratri, polas súas raíces profundas e resistentes. A Enciclopedia Espasa comenta o equivalente refrán castelán da seguinte maneira: "Aconseja no despreciar sistemáticamente las cosas antiguas, que á veces son mejores que las modernas". 
guapa. [Vaca] ben feita. Llópiz recolle Guapes son les vaques como desdén feminino a un piropo.

íngoa / íncoa. "Postema que sale en la región inguinal. Muchas veces se confunde con la fígoa que es llaga purulenta”. Llópiz recóllea en Muras de Eume. Íngoa branca, Deus te desfaga; ingoa negra, Deus te deteña; ingoa rúbea, Deus te consuma (rezuma). / I Íncoa forca foi a (en) Roma; forca veu e íncoa non. íncoa forca! e define íncoa como "incordio, adenitis" (Llópiz 1954a: Medicina, 171). Os dicionarios definen estas palabras como unha simple rexión corporal.

ixola. Habilidade do feirante para mercar barato, vender caro e desfacerse das maulas. A ixola é a nai do choio (Llópiz 1954a: 2,14).

larchán. Tratante de gando. Ao máis larchán / latarego, máis logo danll'un pego (Llópiz 1954a: 2,4). Podería ser que este valor semántico que anota Llópiz fose unha derivación feita polos criadores de gando (sempre rivais dos tratantes de gando) a partir dos significados que para esta palabra son máis comúns: "folgazán” e "tragador de bienes de otros" que recolle Aníbal Otero.

latrica. Plática, sermón. Pregaria nun deserto, latrica perdida. Recollido do sacerdote Nicanor Durán (Llópiz 1954a: Culto religioso, 582,132).

lomba. Lombo. Boi cadeirudo e de lomba ancha, ao seu dono saca da lama (Llópiz 1954a). A palabra lomba aparece nos dicionarios como "corcova, lombo cando ten prominencias" pero refírese sempre a persoas, non ós bovinos que, non sendo de raza Holstein, teñen diversas prominencias.

\section{VARIANTES GRAMATICAIS INFRECUENTES}

A fraseoloxía fai ver que a lingua é máis versátil e maleable do que en abstracto parece. No corpus fraseolóxico batemos frecuentemente con variantes gramaticais que non figuran nos dicionarios. En Home refraneiro, pouco diñeiro o substantivo refraneiro converteuse en adxectivo co valor de "persoa que cre profundamente na verdade dos refráns e que se guía por eles", concepto que tamén expresa o xa citado Home lueiro non é bon *cosecheiro, que ten esta variante: Home moi luneiro, nin moita meda nin moito palleiro.

A fraseoloxía deixa ver non só variacións no vocalismo átono (fígoa) e fenómenos de prótese (afartado, afarto, alapa, apexado, bochar - abochar), senón tamén usos peculiares do número (arroace, aveño), do xénero (galipoto), do seseo (albarás, gradisela) e de sufixos (cadeirudo, cadriludo, catapoia, entrudio, esquinenza, frontudo, galiqueira, lagartola). A necesidade de consegui-la rima autoriza a crear variantes novas (deluvín, lucidio) e a propia categoría gramatical admite metamorfoses varias: entre a natureza substantiva e adxectiva (verémolo en amarelle, carranco), entre verbo e adxectivo (encho) e posiblemente entre verbo e substantivo (dizma).

afartado. [Boi] que deixou de comer ou por farto ou por inapetente. O boi afartado fai cama do rabo (Llópiz 1954a: 1,145). Só Porto (1900-1908) o define como “adj. ant. Harto, farto, mantenido".

Esta palabra e as dúas seguintes son máis comúns sen ese $a$ inicial que parece protético. 
afarto. V. afartado. O boi afarto, déitase no prado (Llópiz 1954a: 1,145). Porto (1900-1908) recolle esta palabra como "adv. c. ant. Asaz, harto, bastante".

alapar. Comer devorando. Deixa que mexe o boi que dos berros alapou (Llópiz 1954a: 1,139). Esta palabra aparece en varios dicionarios pero co valor de "Esconder, ocultar"; só se lle aproxima algo García González (1985) cando o define como “v. (Lax.) gruñir el cerdo cuando tiene hambre”. E a variante alampar aparece por primeira vez en Franco Grande (1968) co valor de "Devorar, engullir (con avidez)", valor que ten como común a forma lapar xa dende Sarmiento.

albarás. Llópiz dá este refrán: Gafeira, albarás e mal de san Antón, tres verbas para un mesme horror. E engade "gafeira, 'lepra'; albarás, 'albarazo o lepra tuberculosa'. Mal de san Antón o gangrena” (Llópiz 1954a: Medicina, 150). En Sarmiento aparece albaraz como "Clase de uvas en Pontevedra". Pero albarazo xa aparece no DRAG (1913-1928) como "s. m. Albarazo. Empeine, postilla, mancha blanca que sale en el cutis de las personas y en la piel de las caballerías. Especie de lepra". E Eladio Rodríguez (1958-1961) di: “s. m. Lepra tuberculosa. / Especie de empeines que forman en la piel manchas blancas. // adj. Uva blanca, grande en ramo y racimo, y no muy temprana”.

amarelle. Os amarelles, é dicir, os narcisos, si que aparecen nos dicionarios pero non vexo o valor de adxectivo, que aparece no substantivo composto anga amarelle co significado de "flores de narciso en infusión". O pan de bróa con anga amarella, fortalez a cervilla e as tripas enche. Cervilla sería a parte cervical do espiñazo humano (Llópiz 1954a: 535,443).

arroace. Arroace na ría, moita sardiña. Vázquez Saco (1962: 18019) di: “Arroace, variante de arroás (M. Valladares) y arroáz (C[arré]. Alvarellos), no registrada en nuestros diccionarios. / Arroace es el delfín, cuya presencia temen nuestros pescadores porque sus saltos son indicio seguro de tormenta y porque ahuyenta la sardina, a la que es muy aficionado. Var. arroaz (Carré, Voc. Irm[andades].; Ibáñez, D.E. [Eladio Rodríguez (1958-1961)]); arroás (Vall[adares]., D.E.) y arruaz. (D.E.) Se le llama también golfiño (D.E.), golfin (D.E.)".

aveño. Calquera instrumento de labranza. Pró ruín traballador non hai aveño que lle veña ben (Vázquez Saco 1962: 22140). Esta forma singular só figura nalgúns dicionarios co valor de "Palo algo labrado para bastón"; pero o significado que lle dá este refrán parece que o reservan para a forma exclusivamente plural e como palabra de varias comarcas de Lugo.

apexado. Pexado. Boi apexado non pasa o valado (Llópiz 1954a: 1,136). Nos dicionarios só aparece como participio de apexar con estes valores: "1. Atravesar el río en barca o barco con el auxilio de una vara o palo que no sea remo. 2. Tratar de agarrar, atarazar, morder o asir con los dientes".

bochar - abochar. "Romper a brotar los árboles. Falta en nuestros diccionarios, como bocho = capullo. Sin: abotoar, abrochar, abotoar, abrollar, abromar, abortar, abrumar, etc." O salgueiro bochou, a primavera entrou (Vázquez Saco 1962: 19913). Pero, se ben se mira, Aníbal Otero recolleu bocho e bochare en Parrochas.

cadeirudo. [Boi] ancho do tercio posterior. Boi cadeirudo e boas illargas, saca ó sen dono da lama (Llópiz 1954a: 1,133). Boi cadeirudo e de lomba ancha ao seu dono saca da lama (Llópiz 1954a: 1,133). Llópiz explica que sacar da lama significa sacar a alguén dunha situación comprometida. Recólleo en Campos de Vila (Quiroga).

cadriludo. V. cadeirudo. Boi cadriludo e de costas anchas ao seu dono saca da lama (Llópiz 1954a: 1,133). O refrán recolle o feito de que o aumento do volume torácico proporciona unha maior resistencia ante calquera esforzo.

carcaixía. "Carcaixía, en Puentedeume, de donde es el refrán, es niebla oscura, húmeda y espesa. Falta en los diccionarios gallegos”. Carcaixía, norte ou nordeste cría (Vázquez Saco 1962: 12844). Carcaixia, norte pía (Vázquez Saco 1962: 12845). Nos dicionarios aparece a forma carcaxía: o propio DRAG (1913-1928) recolle esa forma e ese mesmo refrán (Carcaxía norte cría) que outros posteriores repiten. 
carranco. Llópiz define os carrancos como "Reumáticos que andan arrastrando los pies o piernas, derrengados, nefríticos". Xa se van os carrancos do balneario, sin saúde e sin cartos "Contos de Garibaldi, aludiendo a los agüistas del Balneario de Cortegada, a los que anualmente servía” (Llópiz 1954a: 473,103). Nos dicionarios non aparece esta palabra, aínda que si aparecen carrancudo e carrancholas.

catapoia. Pílula. Catapoia dourada, non por iso millorada (Llópiz 1954a: Medicina, 53). Cuveiro (1876) e Porto (1900-1908) teñen catapocia "píldora". En latín catapotium xa era a "píldora que se envía sen mastigar" mentres que pilula era varias cousas: "pelotiña, bola, píldora e mesmo cagalla".

deluvín. Deluvin é palabra modificada no seu morfema final para consegui-la rima nun fraseoloxismo. Si me encontro no salto, ben me salvo; si vou ó saltarei, inda me salvarei; pero si vou ó delwín, non teñades mentes por min. ¿Que é ese deluvín? Vázquez Saco explica que "deluvar en la zona de Sarria es frotar la ropa para lavarla; y en la comarca de Lalín se aplica a la operación de sacar la vaina, habas, garbanzos, etc., lo que retiene también la idea de frotamiento". E engade este comentario: "Curiosa descripción que hace la pulga de los peligros que corre cuando se intenta cazarla. Se siente perdida si va ô deluvín, palabra procedente de deluvar = 'frotar suavemente, como los niños frotan los ojos al despertarse', ou 'Frotar la ropa cuando se lava, estregar el lino para quitarle las arestas etc.”' (Vázquez Saco 1962: 20471).

dizma. Dizma para a igrexa, anque non quede pelexa. "Dizma lo mismo que desma, diezmo de la Iglesia” (Llópiz 1954a: 578,75). Desma aparece en Carré (1928-1931) pero dižma, substantivo (como parece consideralo Llópiz), non aparece en ningún dicionario. Pero ben podería ser imperativo do verbo dizmar, que, ese si, aparece nos dicionarios.

encho. Soalleiras, mágoas e ceas teñen as covas enchas. Llópiz rexístrao en Forcarei (Llópiz 1954a: 528,385). Este inusual adxectivo aparece en Cuveiro (1876), Porto (1900-1908) e Filgueira (1926), pero só como substantivo co valor de "s.f. Enmienda, compensación, resarcimiento".

entrudio $=$ antroido. Entrudio (antroido) lacazán come a carne e deixa o pan (Vázquez Saco 1962: 7198).

esquinenza. Llópiz defíneo como "anginas, glándulas infartadas". Brétema a rente o chan, esquinenzas dan. Achanda a brétema? Centinelas con esquinenzas. (Dicen en los cuarteles de Galicia que los centinelas en las noches de niebla baja acaban con anginas). Os días de brétema cóllense as esquinenz̧as (Llópiz 1954a: Medicina, 164). Valladares (1884) é o primeiro que rexistra esquinència como "com. Angina en los animales, especialmente caballerías". Despois del recollen todos a forma esquinencia, pero só Aníbal Otero (1977) matiza algo máis cando di: "f. fig. y fam. Parece unha esquinencia, un niño raquítico. Está coma unha esquinencia, un viejo seco”.

estrame. Estrume. Na corte, estrame nova e viño á cova (Llópiz 1954a).

estreveira. Parte da corte onde se moxe a vaca. A vaca de boa teta véndese na estreveira (Llópiz 1954a: 1,156). A vaca de boa teta vese na estreveira (Llópiz 1954a: 1,157). Sendo estreveira o lugar da corte onde se moxen as vacas, a vaca que é boa encherá alí a canada do leite.

fígoa. Chaga infectada. Boi con lagartiña, manta queimada na fígoa (Llópiz 1954a: 1,155). A fígoa designa xenericamente unha chaga infectada, dado que este refrán a refire á lagartiña (enfermidade que carcome a pezuña da vaca) e dado que Valladares (1884) (e outros posteriores a el) a describen como "Especie de heridas, ó llagas, que se forman en la piel, al tiempo de salir las viruelas locas, mas grandes que las de estas, que dan mas trabajo y desaparecen tambien mas tarde". Comentando a palabra ingoa, Llópiz matiza que a fígoa é "llaga purulenta".

frontudo. [Boi] de grandes cornos. Boi, frontudo; e cabalo, cascudo. Indica as cualidades que se prefiren nos animais dunha e da outra especie (Llópiz 1954a) (Eladio Rodríguez 1958-1961: boi).

galipoto. "Cualquier mal venéreo". Galipoto malo, sualo (Llópiz 1954a: Medicina, 489,161). O que traen algúns dicionarios é galipota ("Mal gálico, enfermedad venérea" dende Filgueira 1926) pero temos que prescindir da acepción de "alquitrán", que só recolle Leiras (ca. 1906) e que nos fai 
lembra-lo galipote con que na Costa da Morte denominaban os mariñeiros o chapapote do Prestige do 2002. En calquera caso galipoto aquí é claramente masculino.

galiqueira. "Dolencia venérea". Non [b]ai galiqueira que non veña por bragueta. Dr. Arechaga (Llópiz 1954a: 535,439). Esta denominación do mal gálico non aparece nos dicionarios. Lémbrese no apartado anterior a palabra galipoto.

gradisela. Cando a gaivota anda á gradisela, mal pra nós e fame pra ela (Vázquez Saco 1962: 12610). Pode se-la gradicela que Aníbal Otero recolle en Marín e García González (1985) no Grove co significado de "estrela de mar", se temos en conta que son zonas de seseo. Vázquez Saco (1962) comenta que "Ni gradisela, ni gravisela figuran en nuestros diccionarios" pero gravisela figura en Franco Grande (1968) e Carré (1972) como “semilla en germinación”.

lagartola. Enfermidade que carcome a pezuña da vaca. Vaca con lagartola, tarrón queimado á taxoula (Llópiz 1954a: 1,155). García González (1985) recolle lagartina e lagartixa. Llópiz explica que outro remedio dos albéitares para as chagas dos cascos consistía en aplicar un terrón con céspede fresco e as súas raíces sobre a chaga enconada. É sabido que outro tratamento tradicional para as infeccións e feridas da pezuña (necrobacilose podal) consistía en cortar todo arredor da pata enferma un terrón de herba que logo poñían a secar: segundo ía secando a herba, ía curando a pata.

latarengo. Ladrón de gando. Llópiz (1956) recólleo como adxectivo: xente latarenga. Llópiz recolle as voces latarego e latarengo co significado xeral de "tratante" en Sarria; noutro momento, recolle de Noriega Varela xente latarenga, co mesmo significado: "feriantes, chalanes". Pero cando explica o refrán O que vacas non ten e vende xatiños, de algures lle vén, matiza o concepto de latarengo como "ladrón de ganado" (e faino equivaler ó cast. cuatrero). Lence Santar (1938-1941: 37) escribe, sen dar máis explicacións, que "en Riotorto chaman lataregos ós veciños d'Espasande de Abaixo" e é sabido que Espasande de Baixo é unha das parroquias de Riotorto. Con todo, inicialmente a vOz debía ter un significado neutro, porque en Ribarteme Llópiz recolleu Latarego son que merco e vendo, nin gano nin perdo (Llópiz 1954a: 2,10). Xente latarenga, sexa pobre sexa rica, atópase de feira en feira (Llópiz 1956: 313,689). O ms. de Rodríguez (1855) xa dicía que latarego era "Voz corrompida de Laitariegos, montaña de Asturias donde viven los ganaderos”. É ben posible que haxa aquí unha evolución semántica de tipo metonímico.

lucidío. [Boi] de boa calidade. V. lucido. Boi lucidío, nunca ten fastío (Llópiz 1954a: 1,134). Posiblemente sexa unha creación pedida pola rima, porque a mesma fonte cita Boi lucido, non coñez fastío.

\section{PALABRAS OUUE NON ENCONTRO NO DICIONARIO DE DICIONARIOS}

ababol. "Ababoles, flores o simientes de amapola u otra pap[aver]ácea. Tambien se emplean las hojas como emoliente". Collizo e freumón, pónese [sic] mol con auga d'ababol. Auga d'ababol "cocimiento de simiente de amapola o adormidera” (Llópiz 1954a: Medicina, 65. Ma Pouso. La Vega del Bollo). Cando o collizo te colla, ferve ababoles y enxanga (Ababoles "flores o simientes de amapola u otra pap[aver]ácea. Tambien se emplean las hojas como emoliente”) (Llópiz 1954a Ibidem; Dr. Llópiz Ferrer Repertorio médico).

abregoar. Expulsa-las secundinas. Nove follas de edreira fan abregoar ás femias (Llópiz 1954a: 2,516). Llópiz explica que as fregas se deben dar coa infusión das hedras no ventre. Ignoro se esta palabra terá algo que ver co adxectivo abregada que unicamente recolle Aníbal Otero con esta definición "Defendida, hablando del agua de riego. Trago a i-auga abregada naquela lameira; tem anga pra andar abregada todo o ano (porque la fuente es de él y nadie se la quita). Vale de Matos.

arguía. "Cornezuelo del centeno que entre varias de sus virtudes terapéuticas tiene la de secante". Unto de porco e po d'arguías o fogo negral mailo vermello tira (Llópiz 1954a: Medicina, 156). 
asobardo. Comida excesiva. Repúdeo traino o asobardo (Llópiz 1954a: 522,349). Ata Eladio Rodríguez (1958-1961) non figura sobardar ("Rebasar. Rebordar, salirse alguna cosa de los limites que la contienen. Sobrepasar”).

barbonda. "Especie de reuma articular propia de comarcas muy húmedas. Porque es muy difícil de curar o mitigar la reuma crónica o aguda. En las regiones húmedas existe la barbonda o reuma articular de transición, que se cura cambiando de clima". Dor de barbonda, chuvia á porta. Pra tira-la barbonda, unto das cobras. Derreira vella, a morte a leva (Llópiz 1954a: 472,103). Llópiz recolle esta palabra en Negreira e tamén do Dr. Casares Gil (1882) de quen parece tira-la noticia de que "el unto de cobra (culebra) no faltaba en el botiquín de los menciñeiros, boticas rurales y antros de meigos y hasta se vendía publicamente en las ferias".

benefe. "Violeta o alhelí blanco, también conocido en Gal. por "herba goubeiras y gayos"”. Parece localizalo na Gudiña. O que se cura con "benefes" xa non vai ao méstre (Llópiz 1954a: 505,218).

boeira (estrela). Planeta Venus, segundo Llópiz, por terras de Lourenzá. Estrela boeira, vaite deitar que os vosos boeiros vanse cear (Llópiz 1954a: 1,142). Supoño que a relación cos bois (ou cos pastores: boieiros) está no feito de se-la primeira estrela que se ve ó solpor e a última que desaparece ó mencer (Llópiz 1954a).

couriza. Defluxión nasal. Courizas e cagalleiras acaban cas vellas (Llópiz 1954a: Medicina, 55. Dr. Llopiz Ferrer, Repertorio médico).

culebrón. "Persona mala”. O que mata un culebrón, ten cen anos de perdón (Vázquez Saco 1962: 821).

endriña. "Endriñas falta en nuestos diccionarios, aunque registran endrino". Ano de moitas endriñas, ano de poucas fariñas (Vázquez Saco 1962: 1084). É o froito do endriño (Prunus spinosa).

defrouxeira. Correnza, diarrea. "Si es de pujos se llama defrouxeira; si con cámaras, reeira, correnza y colica. Vulgarmente se le llama cagalleira cagalleira y a la infantil lixo y codo. Correnzas por maio, saúde pra todo o ano. Froita verde pola correnza se perde. Se negra é a defrouxeira, inda máis é a cagalleira. Llópiz comenta neste caso: diferencia entre la diarrea común y la aguda o colerina, furria, furrica, cagalleira (Llópiz 1954a: Medicina, 76) .

escurrutar. Trucar, embestir. O que anda cos bois, a escurrutar deprende (Llópiz 1954a: 1,148). O máis parecido é escurruxar que figura no Apéndice de Eladio Rodríguez (1958-1961) como "v. Espantar, ahuyentar (Lemos)".

esmancarse. Desconxuntarse [unha articulación]. A quen co demo anda, o boi se lle esmanca (Vázquez Saco 1962). O ruin boi na corte folgando s'esmanca (Llópiz 1954a: 1,150).

falamenta. Cháchara mercantil do feirante. Non se fai boa feira sin cartos nin falamenta (Llópiz 1954a: $2,13)^{1}$.

farturado. Suficientemente alimentado. No inverno mormente o gado ha de estar ben alimentado / farto / farturado (Llópiz 1954a: 2,89). Pouco gado e ben farturado (Llópiz 1954a: 2,94). Lémbrense paralelos coma No inverno o gando ha de estar ben mantido (Zamora Mosquera 1972: 149), No inverno sobre todo o gando ha de estar ben comido (Carré Aldao 1926: 35.7, Vázquez Saco 1962).

feirada. Conxunto das operacións económicas realizadas por unha persoa nunha feira. Unha boa feirada cobre moitas malas (Llópiz 1954a: 2,17).

feirado. Feira. Si vas a feirado, ou vai enganar ou volve enganado (Llópiz 1954a: 2,21).

fogo negral. Absceso producido por un hematoma supuroso. Unto de porco e po d'arguías o fogo negral mailo vermello tira (Llópiz 1954a: Medicina, 158).

fogo vermello / aburante. Escarlatina. Unto de porco e po d'arguías o fogo negral mailo vermello tira

1. Llópiz: Non faise bóa feira. 
(Llópiz 1954a: Medicina, 156). Carré (1928-1931): Fogo ardente "Erupción cutánea”. Eladio Rodríguez (1958-1961) fala do Fogo ardente, el fogo de San Antón. Fogo de San Antón, "enfermedad epidémica que hizo grandes estragos en los siglos XI al XVI y que consistía en un ardor cutáneo abrasador y en dolores intolerables, acompañados de una especie de gangrena generalmente mortal. A veces ennegrecía, secaba la piel, extendíase por todo el cuerpo y terminaba por hacer desprenderse las carnes y los huesos". Repíteo sintetizando Franco Grande (1968).

herbado. "Prado". Cal é o herbado, tal é o gado (Llópiz 1954a: 2,95). Llópiz recólleo de C. Agrasar (Agrarismos, Herbón).

larpelo. "Larpelo es en la comarca de Samos, lonja delgada de tocino. Falta en nuestros Diccionarios”. Larpelo cocido, larpelo comido (Vázquez Saco 1962: 10597). Aínda que parece evoca-lo lardo, este é normalmente a parte gorda do touciño, mentres que o larpelo é a delgada.

lourado. "Color de piel melado". Boi marelo lourado, primeiro morto que ampeado. Aplícase á pelaxe do gando vacún (Llópiz 1954a: 1,134).

luareiro. "Que anda con las fases de la luna”. Home luareiro, nin boa palla nin bon palleiro (Vázquez Saco 1962: 11219).

lueiro. "El que anda siempre mirando a la luna para guiarse por sus fases". Home lueiro non é bon

*cosecheiro (Vázquez Saco 1962: 11220). V. na epígrafe 3 a entrada luareiro.

\section{PALABRAS XA POUCO FRECUENTES OU HIBERNADAS}

O refraneiro, como se ve, mantén activas algunhas palabras que xa son pouco frecuentes no uso e mesmo nos dicionarios. Ben mirado, o feito de que un paremiógrafo anote a definición dunha palabra xa indica que el sospeita que pode haber lectores que descoñezan o significado da tal palabra, e que de aí resulte que para eles o refrán sexa opaco. Pero neste apartado quero comentar algunhas palabras que simplemente van quedando desprazadas por outras que resultan simétricas do castelán ou doutras linguas, porque a homologación terminolóxica non sempre privilexia as formas diverxentes, nin sempre ten a debida preocupación por protexe-la variedade.

anazar. Llópiz explica que anazar é bater, axitar, no folklore de Lourenzá. O que anaźa a leite, n'anga a converte (Llópiz 1954a: 1,148). Sol e anga, tempo da anazada. Anazada é o leite callado ou requeixo na fala dos vaqueiros de Alzada (Llópiz 1954a: 2,86). Xa Sarmiento dicía que anaz̧ar é "mover y revolver [un] a cosa para que se condense o trabe, y también para que se liquide o disuelva, o para que se incorporen cuando son muchas cosas, como Bater ou anazar obos".

aprovecer. Noutros casos o fraseoloxismo parece insuflarlle nova vida a unha palabra que si recollen os dicionarios pero que xa parecía un fósil. Tal é o caso do verbo aprovecer. Para Cuveiro era "Aprovechar, hacer progresos"; para Porto (1900-1908), “1. Hacer progresos, adelantar, medrar, aprovechar, crecer, elevarse, desarrollarse. 2. ant. Propagarse, extenderse, multiplicarse, difundirse”; para Carré (1928-1931), “v. n. Adelantar, hacer progresos. Véase arrequecer”; para Acevedo (1932) “Cast. ant.: Aprovechar, hacer progresos. Ús. por los viejos de la montaña del Navia al Eo y en gall. F.”; para Eladio Rodríguez (1958-1961) “1. Aprovecer, aprovechar, 
adelantar, hacer progresos. 2. Cundir, propagarse, difundirse", no Apéndice do Eladio Rodríguez (1958-1961), “v. Aparecer súbitamente (Caurel)”. Os posteriores ou non o recollen xa ou repiten o dito. Ben, pois Llópiz recolle a locución aprovecer como a leite fervendo (Llópiz 1954a: 1,112).

arnelas. "Raigones fuertes de antiguas muelas". Mais val arnelas que móas podremias. L. F. Rev. A.N.T. Cir, 1909 (Llópiz 1954a: 471,99).

aviseda. "Umbría". Na abiseda o zuruxán medra. Este refrán contraponse a aqueloutro que di que Onde entra o sol non entra o médico. Llópiz recólleo en Monforte (Llópiz 1954a: 533,413). Aparece por primeira vez en Eladio Rodríguez (1958-1961).

barandal. "Terraza abalconada". Barandal ao mendía, abóa a vida. Pérez Lama, ref. 1566 (Llópiz 1954a: 536,452).

bochechar. "Enjuagarse la boca, buchear". Bochecha a boca co asento fervido e o dór de móas remargarido (Llópiz 1954a: 471,99).

cegallo. "Cegarrita, persona con poca vista”. Fel do barbo, cúralle a vista aos cegallos (Llópiz 1954a: 514,282).

cercenar. Florea-lo pan. Coma espendoar. Cando o pan cercena, *ablanda a masa na artesa. Cercena: "el hecho de florecer el pan en la tierra”. Variante de cenceno (ver valor) (Vázquez Saco 1962: 17691). "Variante de cenceno que Carré y Dicc. Enc. [Eladio Rodríguez (1958-1961)] sólo aplican a la flor del maíz”. 'Florecer el maíz’ é tamén o significado que o Glosario de Constantino García (1985) recolle en catro lugares da provincia da Coruña. Vázquez Saco (1962) explica que "En esa época [cando o millo florea] hay que dejar la masa un poco dura, porque ablanda".

citra. "Lacra o cicatriz". Cura a fígoa, mais deixa a citra. (Llópiz 1954a: 468,86). Valladares (1884) definía como "Especie de marca, señal, ó abolladura, que hace un objeto en otro y aun la mano del hombre”. A palabra chega a Carré (1928-1931) pero xa non a García González (1985).

cobra. Acción de cobrar. Fun ás cobras e salíronme lagartos. "Fuí a cobrar mis cuentas y no logré mi propósito”. Xoga coa polisemia da palabra cobras (Vázquez Saco 1962: 5986). Aparece por primeira vez en Eladio Rodríguez (1958-1961).

cochicha / cochincha. "Estomatitis, gengivitis, especie de aftas benignas que se presentan a los niños en la lactancia. Recibe además los nombres de boubas, buas, carouxeiras y sársaro. Se hacía respirar a los enfermos, sobre agua previamente pasada por el pío o pilón de los cerdos". "Cochicha, cochicha, vaite d'eiqui que o pórco e a pórca comen de tí. / / Cochincha cocbincha, vaite de aqui que pórcos e pórcas comen de ti (Celanova). Cochincha cochincha, vaite de ehi que os nenos do barrio non son para tí (El habla en Cadones, Bande). Enxunlla de galina tira as cuchichas. Cuchichas en el Valle de Monterrey son las perótidas inflamadas" (Llópiz 1954a: 60). Só Carré (1972) recolle a acepción de 'papera, parótida'.

coitas. "Manchas oscuras en la piel, producidas por disgustos". A pernina (o braciño, o corpiño) de (F. de T.) moi lastimosiña está, de coitas e rábeas e nacidas bravas. Si eres branca Dios te parta, si eres negra Dios te fenda, si eres rubia, Dios te confunda. Salmio, Reiriz - Orense (Llópiz 1954a: 463,63).

coto. De coto escribiu Sarmiento isto cando definiu cadabullo: "Lo último que queda de un tizón (por otro nombre coto) y en general significa un garabullo, un zoquete, un cabo de palo, y creo, del que sirve para alumbrar y quemar". En Valladares (1896) dise "Adición: Pedazo de cigarro, o pitillo. Pedazo inservible de madera". Non volve aparecer ata Carré (1972), que cita Llópiz "cabo de vela" explicando un refrán que recolle dunha fábrica de cera: Con moitos cotos faise un brandón (Llópiz 1954a: Culto religioso, 577,54).

cotoluvía. "Variante de cotovía, cogujada". Cotoluvía, vía, vía, canto máis alta, máis asubía. "El refrán imita el canto del ave. Cotulivía” (Vázquez Saco 1962: 14269). Aparece por primeira vez en Rivas (1978): "f. Calandria, cogujada, ave canora parecida a la alondra (Fondo de Vila y Estevesiños). En 
Fondo de Vila se dice más cotovía. En Estevesiños se dice: Canta a cotoluvía, rompe o día, que alude a sus hábitos mañaneros; en Mayo se oye su canto aéreo casi imperceptible, ya por las cuatro y media. A este hábito aluden también otras lenguas, como el I.: To rise with the lark. En realidad, es una variedad de laverca, pero que habita más por los sembrados, y la laverca por el monte de carrasco rastrero, que en Fondo de Vila llaman carpaz̧a o carpazo".

cuxiga. "Contraveneno, antídoto, triaca". Contra a pezoña malina, cuxiga. Pezoña malina "pústula de aspecto poco confiable; picadura de alimaña venenosa". Dr. R. Segade, Mellid (Llópiz 1954a: $519,324)$.

defumeira. "Fumigación, sahumerio, desinfección por ahumamiento". Defumeira pide o ban onde morreu a enferma. Gómez Durán, "Pract. médico pop.” (Llópiz 1954a: 469,92).

derreira 1. Amalar da derreira "enfermar del riñón". Si non queres amalar da derreira non conteñas a mexarreira (Llópiz 1954a: 511,260).

derreira 2. "Reuma crónica o aguda. Porque es muy difícil de curar o mitigar la reuma crónica o aguda. En las regiones húmedas existe la barbonda o reuma articular de transición, que se cura cambiando de clima". Derreira vella, a morte a leva (Llópiz 1954a: 472,103).

derreo. Mal do derreo "nefritis o reuma". Pra-o mal do derreo, caldo de cogumelos. M. Saavedra Ascariz, Santiago, ref. 1212 (Llópiz 1954a: 473,103). Dor derreado "nefrite". Door derreado trai a morte no rabo. Dr. Blak, Coruña, Folklore de medicina).

enfigoar. "Afistolarse una llaga". Man piedosa, a chaga enfigoa. Escusado en hacer daño al paciente, la llaga no es tratada con la debida energía”. Dr. García Durán, Pract. med. pop. (Llópiz 1954a: 468,87).

escornón. Corneador. Boi escornón recibe cornadas. Acevedo (1932) é o único que recolle a palabra escornón e defínea como "Que tiene condición de topar" (Llópiz 1954a) .

esfarnar. "Florear, purgarse de la flor, expulsar el pendón"; espendoar, en Aguada. Própan esfarnar, o cabelo temblar (Vázquez Saco 1962: 1890).

esforricar. Defecar. Ó solpor esforrical cágase o boi na teiró (Llópiz 1954a: 1,130).

esmechadela. "Descalabradura. Es término irónico". Despois da esmechadela, untal-a cabeza. Asieumedre, L. F., Tio Marcos da Portela 1916 (Llópiz 1954a: 473,104).

esmexarse. "Evacuar orina sin sentirlo". A que caga raleiro e sin querer s'esmexa, por prene se teña. Rafaela Gutierrez, prof. partos - Vigo (Llópiz 1954a: 520,333).

faramalla. A lei de Dios non quer faramallas. "Faramalla: trampa, enredo" (Llópiz 1954a: Dios: 674,8). Se lle habemos facer caso ás fontes escritas, esta ten tódalas trazas de ser unha palabra hibernada. Llópiz recolle o refrán de Bernardino Armesto e dátao en 1834 pero nos dicionarios non aparece ata Aníbal Otero (1977), que o define como "Charla artificial, encaminada a engañar”, e en Eladio Rodríguez (1958-1961), que o define así: "s. f. 1. Faramalla, charla artificiosa encaminada a engañar a uno. 2. Fachenda, bambolla, boato excesivo de más apariencia que realidad. 3. Trapisonda, embrollo, confusión, maraña. En esta acep. también se dice faramallada”. Repíteno despois Franco Grande (1968) e Carré (1928-1931). É curiosa a información que ofrece o TILG: só aparece 11 veces, das que dúas son textos de $1823^{2}$ e de 1853 e outras tres dos últimos once anos; dos últimos

2. Facer vínculos e casas. Recordade, que inda é tempo, Non vos metades en chanzas, que os valentes e o bon viño, Como dicen, logo acaban. ¿Qué ha de darvos ese crego? ¿Qué caudillo é o que vos manda? ¿Un escribano? vergonza E que haxa quen tras del vaia. Pode que teña valor, Como tamén faramalla, Pero ó fin é un escribano Sin opinión e sin fama. De esta xente solo salen Enredos, preitos e trampas. Foron a peste da terra E os ladrós da xente honrada. ¿Queredes saber por qué Contra as leises se levanta? Porque antes a escribanía De Burón daba ganancias. (Poema ós insurrectos de Burón (23.1.1823)). 
vinte anos o TILG ofrécenos tres citas e o CORGA, do CIRP, ofrécenos outras tres. Isto fainos pensar nunha palabra que esmorecía pero que está recuperando a literatura actual.

farón. Preguiceiro, que traballa pouco. Ó boi farón, pouco lle presta o ferrón (Llópiz 1954a: 1,129). Nótese que farona é un dos varios nomes populares da preguiza.

feira franca. Feira boa. O mintir non paga e fai feira franca (Llópiz 1954a: 2,15). Parece ser refrán de Noia. Haberá que lembrar aquí a $6^{a}$ acepción que de franco dá Eladio Rodríguez (1958-1961): "Aplícase a las cosas exceptuadas de derechos y contribuciones, y a los lugares y puertos que gozan de esa exención".

ferradela. Mordida. Ferradela de lozarra, percura a campa. Ferradela de sorropión, percura o queixón. Lozarra "alacrau, escáncere. Rio Caldo, Orense. Son especies distintas aunque ambos nombres lozarra y soropion entran en la misma leyenda. Segun el portugués Alvaro de Acevedo, el sorropion parece ser la cecilia o víbora de los prados. El alacrán, arácnido scorpio, por otros nombres vulgares, besta dos penedos, cancaro, cáncere, escacer, lacrau, lacraio, lescáncere, rabo torto, rapapedras, rascalzo y zábaro, sorropión" (Llópiz 1954a: Zoología, 1006,1).

fianza (venta a). Venda con pago aprazado. Venta ao contado, diñeiro gardo; venta a fianža, diñeiro â balanza (Llópiz 1954a: 2,23). É refrán de Ourense. Só Eladio Rodríguez (1958-1961) recolle indirectamente esta acepción: "2. Obligación que uno hace para seguridad de un pago o contrato. 3. Fianza, prenda que asegura el cumplimiento de una obligación, especialmente si es dinero, que se deposita y consigna".

freumón. "Nombre genérico del flemón de encías, pero más vulgarmente llamado collizoo y colleitizo y boloardo cuando es de gran tamaño; niva se llamaba en el s. XVII". Cocemento de ababois, bóos son pra os freumós (Llópiz 1954a: Medicina, 65. Dr. Andrade Herborística gall.). Collizo flemón en las encías. Auga d'ababol cocimiento de simiente de amapola o adormidera" (Llópiz 1954a: Medicina 65. Ma Pouso. La Vega del Bollo). Collizo e freumón, póñese [sic] mol con auga d'ababol. Auga d'ababol V. 2. s.v. ababol. Boloardo xa aparece en Rodríguez (1863). Freumón é unha interesante evolución semiculta do latín phlegmon, -ōnis, relacionado co grego $\varphi \lambda \varepsilon \gamma \mu \alpha$ e $\varphi \lambda \varepsilon \gamma \mu o w \eta$ que queda varrida polo cultismo normativo flegmón que ninguén di.

galero. Sombreiro. Home de capa e galero é o que eu quero. "La voz galero en el sentido expresado ha casi desaparecido del habla vulgar. La usan de vez en cuando los ancianos. Se pone en boca de las mozas casaderas. Era el hombre a quien tenían por noble y formal, cuyo matrimonio era por lo tanto conveniente" (Vázquez Saco 1962: 11180). Probablemente desapareceu por pensarse que, rematando en -ero, era un castelanismo, cando, se ben se mira, é a palabra latina galerum que xa significaba precisamente "sombreiro". Só a traen Valladares (1884), Filgueira (1926), Carré (1928-1931) e Ibáñez (1950).

gallardo. Lucido e de bo aspecto. Si queres ao boi gallardo, lévao ao lameiro entre febreiro e maio (Llópiz 1954a: 1,153). Fronte ós anteriores lexicógrafos que dan a gallardo o significado de "Que tiene los cuernos largos o a lo alto", Eladio Rodríguez (1958-1961) define como "Airoso, gentil. Bravo, bizarro, valiente".

gandarón. Monte con vexetación pobre ou devesa con monte sen moita costa. Acabada a labor, bois ó gandarón (Llópiz 1954a: 1,142). Franco Grande (1968), Carré (1928-1931) e Ibáñez (1950) reúnen estes significados para gandarón: "s. m. 1. Monte alto que se eleva al final de una gándara. 2. Cumbre que a veces separa dos parroquias".

landra. "Anginas malignas, crup, garrotillo, difteria". Morre o vello cas caimbras e os novos cas landras (Llópiz 1954a: Medicina, 64. O.L. Boado, Méd. Orense). Cuveiro (1876) é o primeiro que trae unha acepción parecida pero que sitúa noutra parte do corpo "Tumor del tamaño de una bellota que se forma en las glándulas, los sobacos, etc.”, que non reaparece ata Eladio Rodríguez (19581961) ("Glándula o quiste del tamaño de una bellota, que suele formarse en el cuello, los sobacos, 
las ingles, etc.”), que reproduce Franco Grande (1968); Carré (1972) di simplemente “Glándula, órgano que sirve para la secreción de humores. Var. Glanda” e reaparece en García González (1985): "Feás: 2. ganglio inflamado en la base del cuello".

lázaro. "Lepra febril". Lázaro, fogo salvaxe, eiqui te pillo, eiqui te mato. Fórmula ensalmista de Mondoñedo. Fogo salvaxe "sarpullido pernicioso" (Llópiz 1954a: 523,354).

lecer. "Buen humor". Deitarse cedo e cedo derguer, dá saúde, forza e lecer."Prevenciones medicas", Dr. Llopiz Ferrer, ref. 758 (Llópiz 1954a: 469,93).

louba. Loa, honor. Aparece na loc. en louva de / na louva de. En louba de san Lois, abogado da teriza, Padre Noso, Ave María. Dr. C. Pelliteiro, El curanderismo (Llópiz 1954a: 529,394). Na louba de san Lois, que me tire ista teriz, e non deixe nada eiquí. H. Gallego Arceste, Carballiño (Llópiz 1954a: 529,394). Na louba de san Gonzalo, pra que torne o pe ao seu estado. Invocación a san Gonzalo de Amarante, "curador" de pes abertos ou desfiados (Llópiz 1954a: 518,320). Na louba de san Tomé, desadormenta o meu pé. "Lo dicen las madres a los niños cuando se les duerme un pie. Castromil de Orense" (Llópiz 1954a: 518,320). En louba de San Silvestre pra que toda meiciña empreste. Sofisma médico farmacéutico. Abon. Dr. Punín (Llópiz 1954a: 507,221). 